\title{
Cancer incidence attributable to air pollution in Alberta in 2012
}

\author{
Abbey E. Poirier MSc, Anne Grundy PhD, Farah Khandwala MSc, Christine M. Friedenreich PhD, \\ Darren R. Brenner PhD
}

See also www.cmajopen.ca/lookup/doi/10.9778/cmajo.20150068

\section{Abstract}

Background: The International Agency for Research on Cancer has classified outdoor air pollution (fine particulate matter [PM $\left.{ }_{2.5}\right]$ ) as a Group 1 lung carcinogen in humans. We aimed to estimate the proportion of lung cancer cases attributable to $\mathrm{PM}_{2.5}$ exposure in Alberta in 2012.

\begin{abstract}
Methods: Annual average concentrations of $\mathrm{PM}_{2.5}$ in 2011 for 22 communities across Alberta were extracted from the Clean Air Strategic Alliance Data Warehouse and were population-weighted across the province. Using $7.5 \mu \mathrm{g} / \mathrm{m}^{3}$ and $3.18 \mu \mathrm{g} / \mathrm{m}^{3}$ as the annual average theoretical minimum risk concentrations of $\mathrm{PM}_{2.5}$, we estimated the proportion of the population above this cut-off to determine the population attributable risk of lung cancer due to $\mathrm{PM}_{2.5}$ exposure.
\end{abstract}

Results: The mean population-weighted concentration of $\mathrm{PM}_{2.5}$ for Alberta in 2011 was $10.03 \mu \mathrm{g} / \mathrm{m}^{3}$. We estimated relative risks of 1.02 and 1.06 for theoretical minimum risk $\mathrm{PM}_{2.5}$ concentration thresholds of $7.5 \mu \mathrm{g} / \mathrm{m}^{3}$ and $3.18 \mu \mathrm{g} / \mathrm{m}^{3}$, respectively. About $1.87 \%-5.69 \%$ of incident lung cancer cases in Alberta were estimated to be attributable to $\mathrm{PM}_{2.5}$ exposure.

Interpretation: Our estimate of attributable burden is low compared to that reported in studies in other areas of the world owing to the relatively low levels of $\mathrm{PM}_{2.5}$ recorded in Alberta. Reducing $\mathrm{PM}_{2.5}$ emissions in Alberta should continue to be a priority to help decrease the burden of lung cancer in the population.

\footnotetext{
T n 2013, an expert panel commissioned by the International Agency for Research on Cancer unanimously agreed that there was sufficient evidence to classify outdoor air pollution as a Group 1 carcinogen for lung cancer in humans. ${ }^{1}$ In addition, the agency classified fine particulate matter with a diameter of $2.5 \mu \mathrm{m}$ or less $\left(\mathrm{PM}_{2.5}\right)$ as carcinogenic to humans (Group 1) after evaluating this component of air pollution separately. ${ }^{1}$ The positive association between exposure to $\mathrm{PM}_{2.5}$ and lung cancer was significant even in areas where the concentrations of $\mathrm{PM}_{2.5}$ were less than the current guidelines based on human health. ${ }^{2}$

Combustion of fossil fuels (mainly in power generation and motor vehicles) gives rise to $\mathrm{PM}_{2.5} \cdot{ }^{3}$ Owing to the very small diameter of this pollutant, it is able to reach deep into lung tissue, causing inflammation in the lungs, blood vessels, and heart and other organs. ${ }^{4}$ To quantify the burden of disease attributable to ambient air pollution in urban areas, the World Health Organization Global Burden of Disease Comparative Risk Factor Assessment examined concentrations of $\mathrm{PM}_{2.5}$ in 3211 cities worldwide for $2000 .^{5}$ Burden of disease
}

was estimated in terms of disability-adjusted life years and deaths. Exposure to $\mathrm{PM}_{2.5}$ was positively associated with lung cancer and cardiopulmonary disease. In an updated report, the World Health Organization estimated that, globally, 3 million deaths in 2012 were attributable to ambient air pollution, of which 402350 were due to lung cancer. ${ }^{6}$ In a recent meta-analysis of large prospective cohort studies, RaaschouNielsen and colleagues ${ }^{2}$ examined the relation between exposure to particulate matter and lung cancer incidence rather than mortality. During the 13-year follow-up of 312944 participants, there were 2095 incident lung cancer cases. For

Competing interests: None declared.

This article has been peer reviewed.

Correspondence to: Darren Brenner, Darren.Brenner@ albertahealthservices.ca

CMAJ Open 2017. DOI:10.9778/cmajo.20160040 
each $10-\mu \mathrm{g} / \mathrm{m}^{3}$ increase in concentration of $\mathrm{PM}_{10}$ exposure, the hazard ratio for all lung cancer types was 1.22. Those authors also completed analyses for subtypes of lung cancer, where exposure to $\mathrm{PM}_{2.5}$ was examined in increments of $5 \mu \mathrm{g} / \mathrm{m}^{3}$, with a hazard ratio of 1.55 for adenocarcinomas. These analyses are of particular interest as a higher proportion of adenocarcinomas develop in nonsmokers, and therefore nonsmokers represent a population of interest when examining risk factors other than smoking. ${ }^{7}$

In Alberta in 2012, lung cancer accounted for $12 \%$ of all incident cancers, ${ }^{8}$ making it the third most frequently diagnosed cancer. Although smoking is known to be the main cause of lung cancer, it is relevant for public health efforts to explore other risk factors for lung cancer. In the present study, we used population attributable risk estimates to estimate the proportion and absolute number of incident lung cancer cases attributable to $\mathrm{PM}_{2.5}$ exposure in Alberta in 2012.

\section{Methods}

This manuscript is part of a series of exposure-specific manuscripts concerning the proportion of cancer cases attributable to modifiable lifestyle and environmental risk factors in the general population of Alberta. The methodologic framework for this series has previously been described. ${ }^{9}$

\section{Prevalence of exposure}

We extracted average concentrations of $\mathrm{PM}_{2.5}$ for 22 communities with complete data in Alberta for 2011 from the Clean Air Strategic Alliance Data Warehouse (now the ambient air quality data warehouse). ${ }^{10}$ The $\mathrm{PM}_{2.5}$ concentration data from these communities cover $78 \%$ of Alberta's population. Concentrations of $\mathrm{PM}_{2.5}$ recorded in the database are collected by air-monitoring stations that obtain hourly measurements. All outdoor air quality data undergo quality-control and quality-assurance procedures. For communities with more than 1 monitoring site, we used an average across sites. We weighted the annual average $\mathrm{PM}_{2.5}$ concentrations to the population based on the census population estimates for each community for $2011^{11}$ using the following formula:

Population-weighted $\mathrm{PM}_{2.5}$ estimate $=($ community population/Alberta population) $\times$ community annual average $\mathrm{PM}_{2.5}$ concentration

We then summed the community population-weighted $\mathrm{PM}_{2.5}$ estimates to obtain an overall average $\mathrm{PM}_{2.5}$ concentration estimate for Alberta in 2011.

\section{Relative risk estimation}

As risk estimates for the association between $\mathrm{PM}_{2.5}$ and lung cancer were not readily available for Alberta, we used the following equation, originally developed for the World Health Organization's Global Burden of Disease study, ${ }^{12}$ to determine the relative risk (RR) for the outcome of lung cancer incidence associated with population-weighted $\mathrm{PM}_{2.5}$ exposure in Alberta:

Equation 1: $\mathrm{RR}=e^{[\beta \times(C-7.5 \mu g / m 3)]}$

where RR is the relative risk for lung cancer associated with $\mathrm{PM}_{2.5}$ exposure, $C$ is the population-weighted mean concentration of $\mathrm{PM}_{2.5}$, and $\beta$ is the slope of the linear concentrationresponse function for $\mathrm{PM}_{2.5}$ exposure and lung cancer $(\beta=$ 0.00789 , standard error $=0.003447)$ from Pope and colleagues ${ }^{13}$ and Ostro. ${ }^{14}$ In the Global Burden of Disease analysis, Cohen and colleagues ${ }^{12}$ estimated that the risk of mortality due to $\mathrm{PM}_{2.5}$ exposure increases linearly over a range of counterfactual average annual concentrations of $7.5 \mu \mathrm{g} / \mathrm{m}^{3}$ to a maximum of $50 \mu \mathrm{g} / \mathrm{m}^{3}$. Therefore, we used a theoretical minimum risk concentration of $7.5 \mu \mathrm{g} / \mathrm{m}^{3}$ for $\mathrm{PM}_{2.5}$ exposure in equation 1 .

\section{Population attributable risk estimation}

The RRs estimated from equation 1 were then used in equation $2^{15}$ to estimate the population attributable risk for Alberta:

$$
\text { Equation 2: PAR }=P(R R-1) / P(R R-1)+1
$$

where PAR is the population attributable risk, $P$ is the prevalence of exposure (proportion of population exposed to populationweighted mean $\mathrm{PM}_{2.5}$ concentrations above $7.5 \mu \mathrm{g} / \mathrm{m}^{3}$ in the area of interest) and $R R$ is as estimated above in equation 1 . We also used Monte Carlo simulation methods to estimate $95 \%$ confidence intervals (CIs) for the population attributable risk estimates, as described above. We then multiplied the population attributable risk by the lung cancer incidence for 2012, acquired from the Alberta Cancer Registry, to estimate the number of excess attributable cases of lung cancer due to $\mathrm{PM}_{2.5}$ exposure. The Alberta Cancer Registry is certified by the North American Association of Central Cancer Registries and has consistently achieved Gold Certification for "completeness of the data, timely reporting and other measures that judge data quality."

We used Monte Carlo simulation methods to determine uncertainty ranges around point estimates and specified a lognormal distribution for the RR estimates (equation 1), based on the standard errors published in studies by Cohen and colleagues $^{12}$ and Pope and colleagues. ${ }^{13}$ We drew 10000 samples and used the 2.5th and 97.5th percentiles of the resulting population attributable risk distribution as the lower and upper limits of a $95 \%$ CI.

\section{Sensitivity analysis}

Since $54 \%$ of the communities in Alberta had recorded concentrations of $\mathrm{PM}_{2.5}$ below the theoretical minimum risk of $7.5 \mu \mathrm{g} / \mathrm{m}^{3}$, we completed a sensitivity analysis using a counterfactual concentration of $\mathrm{PM}_{2.5}$ at the minimum observed concentration of $3.18 \mu \mathrm{g} / \mathrm{m}^{3}$ in equation 1 . We then used the $\mathrm{RR}$ estimate to estimate the population attributable risk for a theoretical minimum risk of $3.18 \mu \mathrm{g} / \mathrm{m}^{3} \mathrm{PM}_{2.5}$. We conducted all analyses using $\mathrm{R}$ (version 3.2.3) and RStudio (version 0.98.1080) (RStudio, Inc.). 


\section{Ethics approval}

Ethics approval was obtained from the Conjoint Health Research Ethics Board, University of Calgary.

\section{Resullts}

The mean population-weighted $\mathrm{PM}_{2.5}$ concentration for Alberta in 2011 was $10.03 \mu \mathrm{g} / \mathrm{m}^{3}$ (Table 1). Based on annual average concentrations, an estimated $94.2 \%$ of the population in Alberta was exposed to $\mathrm{PM}_{2.5}$ levels above $7.5 \mu \mathrm{g} / \mathrm{m}^{3}$ in 2011. The RR of lung cancer due to $\mathrm{PM}_{2.5}$ exposure estimated using equation 1 was 1.02 . Using equation 2 , we estimated the population attributable risk of lung cancer due to $\mathrm{PM}_{2.5}$ exposure in Alberta to be $1.87 \%$ (95\% CI $0.22 \%-3.36 \%$ ). Of the 1952 incident lung cancer cases diagnosed in 2012, 36 (95\% CI 4-66) were estimated to be attributable to $\mathrm{PM}_{2.5}$ exposure.

In our sensitivity analysis, the RR of lung cancer due to $\mathrm{PM}_{2.5}$ exposure over $3.18 \mu \mathrm{g} / \mathrm{m}^{3}$ was 1.06 , resulting in a population attributable risk of $5.69 \%$ (111 incident cases in 2012).

\section{Interpretation}

In the current analysis, we estimated RRs of 1.02 and 1.06 for the relation between exposure to $\mathrm{PM}_{2.5}$ and lung cancer using the theoretical minimum risk levels of $7.5 \mu \mathrm{g} / \mathrm{m}^{3}$ and $3.18 \mu \mathrm{g} /$ $\mathrm{m}^{3}$, respectively. In a 2014 meta-analysis including 14 studies, the summary RR for lung cancer associated with a $10-\mu \mathrm{g} / \mathrm{m}^{3}$ change in $\mathrm{PM}_{2.5}$ exposure was estimated to be $1.09,{ }^{16}$ which is consistent with our results. Also consistent with our RR estimates, a large Canadian-based cohort study estimated a hazard ratio of 1.03 for trachea, bronchus and lung cancers due to $\mathrm{PM}_{2.5}$ exposure. ${ }^{17}$ Using our RR estimates, we estimated that $1.87 \%$ (36 cases) to $5.69 \%$ (111 cases) of incident lung cancer in Alberta in 2012 were attributable to $\mathrm{PM}_{2.5}$ exposure. Norman and colleagues ${ }^{18}$ completed a similar study in South Africa using the same methods as in the current study and estimated that $5.1 \%$ of mortality from cancers of the trachea, bronchus and lung in adults could be attributed to outdoor air pollution $\left(\mathrm{PM}_{2.5}\right.$ and $\left.\mathrm{PM}_{10}\right)$, which is more consistent with our sensitivity analysis results. The higher population attributable risk estimate in South Africa is expected, as the populationweighted mean concentration of $\mathrm{PM}_{2.5}$ was $26.6 \mu \mathrm{g} / \mathrm{m}^{3}$ in that country, compared to $10.0 \mu \mathrm{g} / \mathrm{m}^{3}$ in Alberta.

In 2014, Burnett and colleagues ${ }^{19}$ estimated the population attributable risks for mortality due to lung cancer. They measured exposure estimates for $\mathrm{PM}_{2.5}$ between 2001 and 2005 in 187 countries. The population attributable risk for 2005 ranged from less than $1 \%$ to $25 \%$ depending on the ambient $\mathrm{PM}_{2.5}$ levels in the country; most countries had a population attributable risk between $0 \%$ and $10 \%$, which is consistent with our findings given the low levels of $\mathrm{PM}_{2.5}$ measured in Alberta. Hystad and colleagues ${ }^{20}$ conducted a case-control study in Canada to examine the association between longterm residential exposure to air pollution and lung cancer. They measured annual residential exposure to $\mathrm{PM}_{2.5}$ over a 20-year period. After adjustment for a comprehensive set of individual and geographic covariates, the odds ratio for incident lung cancer was 1.29 for each $10-\mu \mathrm{g} / \mathrm{m}^{3}$ increase in $\mathrm{PM}_{2.5}$ concentration. This is higher than the RR of 1.05 estimated in the current study, which is most likely due to the duration of exposure and covariates (including smoking status) included in the model for the case-control study. Several cohort studies have also examined the relation between exposure to outdoor air pollution and lung cancer. As part of the American Cancer Society Cancer Prevention Study II, $\mathrm{PM}_{2.5}$ exposure concentrations were collected from monitoring stations in urban areas and applied to about 860000 participants based on reported areas of residence. ${ }^{21}$ The risk of mortality from lung cancer was shown to increase by $8 \%$ for every $10-\mu \mathrm{g} / \mathrm{m}^{3}$ increase in $\mathrm{PM}_{2.5}$ concentration. This positive association was stronger among never smokers, in whom the risk of lung cancer mortality increased by $15 \%-27 \%$ for each $10-\mu \mathrm{g} / \mathrm{m}^{3}$ increase in $\mathrm{PM}_{2.5}$ exposure. ${ }^{22}$ Information on mobility (i.e., history of address changes) was not available for the current

\begin{tabular}{|c|c|c|}
\hline Community & Population* & $\begin{array}{c}\text { Mean } \mathrm{PM}_{2.5} \\
\text { concentration, } \\
\mu \mathrm{g} / \mathrm{m}^{3}\end{array}$ \\
\hline Anzac & 585 & 5.18 \\
\hline Beaverlodge & 2365 & 6.72 \\
\hline Bruderheim & 1155 & 8.22 \\
\hline Calgary & 1214839 & 10.82 \\
\hline Caroline & 501 & 4.18 \\
\hline Cold Lake & 13839 & 5.71 \\
\hline Drayton Valley & 7049 & 7.24 \\
\hline Edmonton & 1159869 & 9.75 \\
\hline Edson & 8475 & 3.79 \\
\hline Elk Point & 1412 & 8.22 \\
\hline Fort Chipewyan & 847 & 3.18 \\
\hline Fort McKay & 562 & 9.76 \\
\hline Fort McMurray & 61374 & 8.6 \\
\hline Fort Saskatchewan & 19051 & 6.51 \\
\hline Grande Prairie & 55032 & 8.42 \\
\hline Hinton & 9640 & 7.89 \\
\hline Lamont County & 3872 & 7.28 \\
\hline Lethbridge & 105999 & 6.76 \\
\hline Medicine Hat & 72807 & 7.85 \\
\hline Red Deer & 90564 & 13.65 \\
\hline Redwater & 1915 & 5.39 \\
\hline Tomahawk & 65 & 3.23 \\
\hline $\begin{array}{l}\text { Alberta (population } \\
\text { weighted)* }\end{array}$ & 2831752 & 10.03 \\
\hline
\end{tabular}


study, and, therefore, we did not have any measures of longterm exposure or duration of exposure for $\mathrm{PM}_{2.5}$.

Our population attributable risk estimate was lower than that in similar studies conducted globally. ${ }^{18,21,22}$ This can be explained by several factors including the relatively low levels of ambient $\mathrm{PM}_{2.5}$ recorded in Alberta. The global burden of disease studies revealed a great deal of variation in population attributable risk estimates across the world, owing to vast differences in $\mathrm{PM}_{2.5}$ concentrations as a result of the variations in population density, industry and urban/rural divisions within the countries studied.,19 The greatest burden of disease occurred in areas of rapid population growth in the developing world. Therefore, although those authors estimated that $5 \%$ of lung cancer mortality could be attributable to $\mathrm{PM}_{2.5}$ exposure globally, estimates for less-dense populations in developed countries are most likely lower.

\section{Limitations}

Assessment of $\mathrm{PM}_{2.5}$ exposure for the current study was based on the available data from the Clean Air Strategic Alliance monitoring network. Unlike land-use regression models of air pollution, our study used raw estimates that did not account for mobility, green space, proximity to major roads and other variables associated with the built environment. In a study comparing models of $\mathrm{PM}_{2.5}$ concentration in the New York City region, land-use regression models slightly outperformed geostatistics (used in the current study) in predicting concentrations at validation sites. As a measure of validation of the models, the root mean squared error at prediction sites was $1.15 \mu \mathrm{g} / \mathrm{m}^{3}$ for land-use regression and $1.30 \mu \mathrm{g} / \mathrm{m}^{3}$ for geostatistics. ${ }^{23}$ In addition, in the current study, the air-monitoring stations with complete data did not cover the entire province of Alberta. Based on Canadian census data, the population of Alberta in 2011 was 3645 257, and the airmonitoring stations covered only 2831752 Alberta residents. In future analyses, our team will aim to estimate the burden of cancer attributable to air pollution at the national level. We will improve on the present analyses by considering more pollutants such as nitrogen dioxide and using measures of air pollution with accurate spatial and temporal properties, such as those from the Canadian Census Health and Environment Cohort presented in the recent work of Crouse and colleagues. ${ }^{17}$

We assumed that the impact of $\mathrm{PM}_{2.5}$ on lung cancer is uniform across tobacco consumption groups. Given the clear association between tobacco use and lung cancer, if this assumption is not true, our population attributable risk estimates may be an over- or underestimation for certain tobacco consumption groups. It should also be noted that information on occupation was not taken into account. Thus, the proportion of Albertans working outside of their census community was unknown and may have led to inaccurate exposure assignments. Finally, latency was not taken into account in the current study. Latency is an important factor, as lung cancer risk is known to increase after years of exposure to air pollution. ${ }^{1}$ Although we used pollution estimates from 2011 to account for temporality, most previous studies included over 5 years of air pollution exposure. Owing to insufficient data availability, this was not possible for the current study. However, average annual concentrations of $\mathrm{PM}_{2.5}$ in Canada were stable between 2000 and 2014, with a range of 5.9$7.7 \mu \mathrm{g} / \mathrm{m}^{3} .^{24}$

\section{Conclusion}

The current analysis estimates that about 2\%-6\% of incident lung cancer cases in Alberta in 2012 may be attributable to $\mathrm{PM}_{2.5}$ exposure. Our estimate is within the expected range; however, with better exposure assessment, we could be more confident in our quantification of the risks associated with both acute and long-term $\mathrm{PM}_{2.5}$ exposure. Although a minority of all deaths caused by outdoor air pollution are due to lung cancer, valid air pollution estimates are essential for studying the associations between air pollution and all chronic disease. Future studies focusing on long-term air pollution exposure are essential to understanding the relation between air pollution and chronic disease.

\section{References}

1. Outdoor air pollution. Lyon (FR): International Agency for Research on Cancer; 2016. Available: http://publications.iarc.fr/Book-And-Report-Series/Iarc -Monographs-On-The-Evaluation-Of-Carcinogenic-Risks-To-Humans/ Outdoor-Air-Pollution-2015 (accessed 2017 Mar. 6).

2. Raaschou-Nielsen O, Andersen ZJ, Beelen R, et al. Air pollution and lung cancer incidence in 17 European cohorts: prospective analyses from the European Study of Cohorts for Air Pollution Effects (ESCAPE). Lancet Oncol 2013;14: 813-22.

3. Holman C. Sources of air pollution. In: Holgate ST, Samet JM, Koren HS, et al., editors. Air pollution and health. London (UK): Academic Press; 1999:115-48.

4. Saldiva PH, Clarke RW, Coull BA, et al. Lung inflammation induced by concentrated ambient air particles is related to particle composition. Am 7 Respir Crit Care Med 2002;165:1610-7.

5. Cohen AJ, Ross Anderson H, Ostro B, et al. The global burden of disease due to outdoor air pollution. 7 Toxicol Environ Health A 2005;68:1301-7.

6. Ambient air pollution: a global assessment of exposure and burden of disease. Geneva: World Health Organization; 2016. Available: http://apps.who.int/iris/ bitstream/10665/250141/1/9789241511353-eng.pdf (accessed 2017 Jan. 30).

7. Schuller HM. Mechanisms of smoking-related lung and pancreatic adenocarcinoma development. Nat Rev Cancer 2002;2:455-63.

8. 2012 report on cancer statistics in Alberta: cancer in Alberta. Edmonton: CancerControl Alberta, Alberta Health Services; 2015. Available: www.albertahealthservices. ca/assets/healthinfo/poph/hi-poph-surv-cancer-cancer-in-alberta-2012.pdf (accessed 2014 Dec. 18).

9. Grundy A, Friedenreich CM, Poirier AE, et al. A methodologic framework to evaluate the number of cancers attributable to lifestyle and environment in Alberta. CMA7 Open 2016;4:E471-8.

10. Clean Air Strategic Alliance Data Warehouse. 2011. Edmonton: Alberta Government; 2011. Available: www airdata alberta.ca/ (accessed 2014 Oct. 30).

11. Census of Canada. 2011. Ottawa: Statistics Canada; 2011. Available: www12. statcan.gc.ca/census-recensement/2011/dp-pd/index-eng.cfm (accessed 2014 Oct. 30).

12. Cohen AJ, Anderson HR, Ostro B, et al. Urban air pollution. In: Ezzati E, Lopez AD, Rodgers A, et al., editors. Comparative quantification of bealth risks: global and regional burden of disease attributable to selected major risk factors. Vol. 2. Geneva: The World Health Organization; 2004:1353-433.

13. Pope CA 3rd, Burnett RT, Thun MJ, et al. Lung cancer, cardiopulmonary mortality, and long-term exposure to fine particulate air pollution. $7 A M A$ 2002;287:1132-41.

14. Ostro B. Outdoor air pollution: assessing the environmental burden of disease at national and local levels. Environmental Burden of Disease series, no. 5. Geneva: World Health Organization; 2004.

15. Levin ML. The occurrence of lung cancer in man. Acta Unio Int Contra Cancrum 1953;9:531-41.

16. Hamra GB, Guha N, Cohen A, et al. Outdoor particulate matter exposure and lung cancer: a systematic review and meta-analysis. Environ Health Perspect 2014;122:906-11.

17. Crouse DL, Peters PA, Hystad P, et al. Ambient $\mathrm{PM}_{2.5}, \mathrm{O}_{3}$, and $\mathrm{NO}_{2}$ exposures and associations with mortality over 16 years of follow-up in the Canadian Census Health and Environment Cohort (CanCHEC). Environ Health Perspect 2015;123:1180-6. 
18. Norman R, Cairncross E, Witi J, et al. Estimating the burden of disease attributable to urban outdoor air pollution in South Africa in 2000. S Afr Med 7 2007;97:782-90.

19. Burnett RT, Pope CA, Ezzati M, et al. An integrated risk function for estimating the global burden of disease attributable to ambient fine particulate matter exposure. Environ Health Perspect 2014;122:397-403.

20. Hystad P, Demers PA, Johnson KC, et al. Long-term residential exposure to air pollution and lung cancer risk. Epidemiology 2013;24:762-72.

21. Krewski D, Jerrett M, Burnett RT, et al. Extended follow-up and spatial analysis of the American Cancer Society study linking particulate air pollution and mortality. HEI Research Report 140. Boston: Health Effects Institute; 2009.

22. Turner MC, Krewski D, Pope CA 3rd, et al. Long-term ambient fine particulate matter air pollution and lung cancer in a large cohort of never-smokers. Am 7 Respir Crit Care Med 2011;184:1374-81.

23. Ross Z, Jerrett $M$, Ito $K$, et al. A land use regression for predicting fine particulate matter concentrations in the New York City region. Atmos Environ 2007; 41:2255-69.

24. Canadian environmental sustainability indicators: air quality (2016). Gatineau (QC): Environment and Climate Change Canada; 2016. Available: www.ec. gc.ca/indicateurs-indicators/default.asp?lang=en\&n=7DCC2250-1 (accessed 2017 Jan. 30).

Affiliations: Department of Cancer Epidemiology and Prevention Research (Poirier, Grundy, Khandwala, Friedenreich, Brenner), CancerControl Alberta, Alberta Health Services; Department of Oncology (Friedenreich, Brenner) and Department of Community Health Sciences (Friedenreich, Brenner), Cumming School of Medicine, University of Calgary, Calgary, Alta.
Contributors: Christine Friedenreich and Darren Brenner were responsible for the study conception. Abbey Poirier was responsible for acquisition of the data, and Farah Khandwala and Abbey Poirier analyzed the data. All authors contributed substantially to the study design and interpretation of the data, prepared the manuscript, approved the final version to be published and agreed to act as guarantors of the work.

Funding: This project was funded by the Alberta Cancer Prevention Legacy Fund. The funder played a role in the conception and design of the study. The funder had no role in the collection, analysis or interpretation of the data or the writing of the manuscript. Christine Friedenreich is supported by an Alberta Innovates - Health Solutions Health Senior Scholar Award and the Alberta Cancer Foundation Weekend to End Women's Cancers Breast Cancer Chair at the University of Calgary. Darren Brenner is supported by a Capacity Development Award in Prevention (no. 703917) from the Canadian Cancer Society Research Institute.

Acknowledgements: The authors gratefully acknowledge Laura McDougall from the Alberta Cancer Prevention Legacy Fund for her support and guidance. The authors also thank Bethany Kaposhi and Lorraine Shack from the Alberta Cancer Registry for providing cancer incidence data.

Supplemental information: For reviewer comments and the original submission of this manuscript, please see www.cmajopen.ca/content $/ 5 / 2 /$ E524/suppl/DC1 